\title{
Performance Evaluation of Model Predictive Current Controlled Grid Tied Converter for Sampling Frequency Variations
}

\author{
Bhadra R. Warrier, A. Vijayakumari and Sasi K Kottayil \\ Department of Electrical and Electronics Engineering \\ Amrita School of Engineering, Coimbatore \\ Amrita Vishwa Vidyapeetham, India \\ bhadrammupwe@gmail.com, a_vijayakumari@cb.amrita.edu,kk_sasi@cb.amrita.edu
}

\begin{abstract}
Model predictive control is identified as one of the emerging control platforms which can replace the classical linear as well as sliding mode controls of power converters and drives. Implementing this algorithm in grid tied converter control imposes its design parameters like sampling frequency, cost function coefficients, model parameters etc. to be aptly chosen to match with hardware intricacies. Therefore, a detailed investigation for the interoperability of various MPC design parameters and the relative performance across each case is felt necessary. This paper presents one such primary investigation carried out in the pre-experimentation stage to identify the correlation between sampling rates of model predictive control for desired performance indices like tracking accuracy, average inverter switching frequency, current harmonic profile and inverter power loss applied to a three phase grid connected inverter. While implementing the control, a discrete time model representing a $15 \mathrm{~kW}$ grid tied inverter is developed for current prediction followed by a suitable cost function formulation aimed at accurate reference tracking. From the analysis, it is observed that the tracking accuracy greatly depends on the prediction interval, which in turn depends on the sampling rates. The inverter is tested for its dynamic performance by considering step change in reference and source specifications besides steady state analysis. Extensive analysis for various combinations of MPC design parameters and their relative performance merits on the inverter output is presented. The results exhibited high reference tracking accuracy with improved harmonic profile for high to moderate sampling frequencies, but with a tax on the inverter efficiency. The choice of switching frequency for a trade-off between high tracking accuracy and inverter efficiency is also suggested.
\end{abstract}

Keywords: Grid tied inverter, model predictive control, tracking accuracy, sampling rates, switching loss, harmonic profile.

\section{Introduction}

Control of three phase grid connected inverters is an extensively researched area with new techniques emerging rapidly. Conventionally, almost all of these involves in voltage or current control of inverters to achieve set targets [1-3]. Current controls of inverter ensure that the load current delivered will follow the reference current with minimum error. Such errors in terms of the current amplitude, form and phase are the key factors in classifying the performance of various techniques. Control strategies, both linear and non-linear, often utilize a pulse width modulator to convert the reference voltage into control signals at a desired switching frequency. Higher switching frequencies are often preferred for improved performance, at the same time they cause higher switching power losses [4] and reduced efficiency. Thus, the optimum choice of switching frequency to efficiency is still a vital design trade off. Of late, a class of nonlinear implicit modulation technique has emerged which does not need a modulator to obtain actuation unlike aforementioned current control techniques. Such a nonlinear control has better tracking performance with good dynamic response, but suffers from issues like variable switching frequency requiring increased filter size. [4-8].

Received: November $13^{\text {th }}, 2018$. Accepted: June $24^{\text {th }}, 2019$

DOI: 10.15676/ijeei.2019.11.3.1 
Model Predictive Control (MPC) [9-16] an offshoot of nonlinear predictive control is an approach capable of achieving additional secondary control targets besides reference tracking. MPC has the potential to eliminate major drawbacks like inability to accommodate system model, discontinuous control signal etc. of other nonlinear controls like hysteresis control, sliding mode control etc. thus emerged as an attractive choice for the future grid connected inverter control [9-10,17].

MPC is a sample-based technique in which a mathematical model of the system under consideration is used to iteratively predict control variables and optimize it to meet the control constraints. MPC is able to handle system nonlinearities and control constraints simultaneously besides its primary control requirement. This is in contrast to the classical linear controllers which often try to neglect or simplify system nonlinearities and there will be always a compromise on the reference tracking when attempted for higher inverter efficiencies. However, selection of iteration size, optimization tuning etc. are crucial while working with MPC to ensure accurate control. Hence a deeper and extensive analysis of this emerging control technique is of vital significance so that proper selection of digital controllers with adequate capabilities, filter selection and heat sink sizing can be accomplished for its real time implementation. This work analyzes the performance of MPC based grid tied inverter with varying sampling rates in terms of tracking capability, harmonic profile and total inverter power loss.

Section II describes the MPC algorithm developed for three phase grid tied inverter in detail followed by simulation and performance analysis discussion in section III.

\section{MPC Algorithm for three phase grid connected inverter}

MPC is a nonlinear control that employs prediction and optimization features to achieve multiple control targets which are weighted as per the application demand. Essentially, it is a receding horizon [16] optimization problem that utilizes discrete time or state space model of the system to predict the future behavior of control variables until a horizon in time.

The optimal actuation to reflect the necessary control action is provided based on minimizing a cost function, where the cost function represents the desired target to be attained by the control as,

$$
g=f_{m}+\lambda f_{n}
$$

where, $f_{m}$ and $f_{n}$ represents the primary and secondary target respectively and $\lambda$ is a weighting parameter. The cost function ( $g$ ) in equation (1) is a combination of various sub-functions catering to multiple control requirements. Some of these sub-functions represents the hard constraint or primary target and others form soft constraint or secondary targets. Some common primary targets chosen include current, power, torque etc. [4,11]. Besides the primary targets, in several applications, the converters are expected to accomplish secondary targets such as switching frequency reduction [4], harmonic profile improvement [4], reactive power control [4], flux control, capacitor voltage balancing for multilevel inverters [4] etc. In MPC, both the primary functions and the secondary functions are achieved with a single cost function. The strict optimization of $f_{m}$, results in accurate reference tracking, while the secondary targets are prioritized based on the requirement of the auxiliary performance improvements by using the weighting parameter.

A mathematical model of the inverter system is developed to carry out the predictions and subsequent optimization to establish MPC.

\section{A. Mathematical Modeling of Grid Tied Inverter System}

In typical grid tied inverters an outer control loop of power or dc link voltage will provide an equivalent current reference for inner loops. But the present work targets to analyze the performance of the MPC algorithm for its tracking accuracy for variations in the iteration size through sampling frequency variations. So, the outer loop is not considered exclusively. However, a predefined current reference representing an intended active-reactive power to be 
delivered to the grid is assumed and the MPC algorithm is tested for its steady state and transient performance.

The algorithm execution begins with the development of a mathematical model of the grid tied inverter system under test. The so developed model predicts the possible output current values for every inverter switching state applied to it and pass these pre-selections for further optimization with the defined cost function. Furthermore, this cost function optimization process in turn suggests the switching state of inverter to be applied to the successive iteration to achieve the desired target/s.

The block diagram of the grid tied inverter system with the MPC considered for the proposed study is shown in Figure. 1 with $\mathrm{V}_{\mathrm{DC}}$ representing the input dc voltage. A sample reference current, $i^{*}(k)$ and the actual current, $i(k)$ are the inputs to the proposed MPC controller, whereas the selected switching state is the output.

Applying KVL at the inverter output, the load current dynamics can be expressed as shown,

$$
v_{x N}=L \frac{d i_{x}}{d t}+R i_{x}+v_{G x}+v_{n N}
$$

where, $v_{\mathrm{xN}}(\mathrm{x}=\mathrm{a}, \mathrm{b}, \mathrm{c})$ is the inverter pole voltages, $\mathrm{v}_{\mathrm{xG}}$ is the grid phase to neutral voltages, $v_{n N}$ is the voltage between load and grid neutral, $i_{X}$ is the phase currents of inverter, $R$ is the filter resistance and $L$ is the filter inductance.

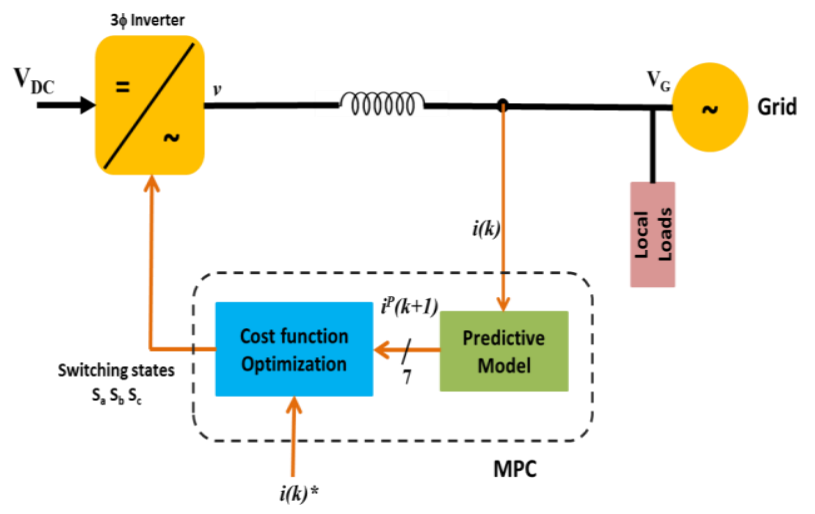

Figure 1. Schematic of Three phase grid tied inverter with MPC

Equation (2) is represented in space vector form as,

$$
v=L \frac{d i}{d t}+R i+\hat{v}_{G}
$$

where $\mathrm{v}$ is the space vector of inverter output voltage, $\hat{v}_{G}$ is the peak grid voltage and $\mathrm{i}$ is the load current vector.

Alternatively, the inverter voltage vector is expressed using the switching states $\left(\mathrm{s}_{\mathrm{a}}, \mathrm{s}_{\mathrm{b}}, \mathrm{s}_{\mathrm{c}}\right)$ and DC input voltage as,

$$
v=V_{D C}\left(s_{a}+a s_{b}+a^{2} s_{c}\right)
$$

Where, $a=e^{j 2 \pi / 3}$ and $s_{a}, s_{b}, s_{c}$ represents the status of the top switches of inverter legs. Thus, a three phase inverter with six switches will have eight possible voltage vectors represented as $\mathrm{v}_{0}$ to $\mathrm{v}_{7}$, from 000 to 111 .

Converting equation (3) into its discrete time model by applying Euler's approximation with a sampling time $T_{s}$ gives,

$$
\begin{aligned}
& \frac{d i}{d t} \approx \frac{i(k+\boldsymbol{I})-i(k)}{T_{s}} \\
& v(k)=L\left(\frac{i(k+\boldsymbol{I})-i(k)}{T_{s}}\right)+R i(k)+\hat{v}_{G}(k) \\
& i(k+\boldsymbol{I})=\left(\boldsymbol{I}-\frac{R T_{s}}{L}\right) i(k)+\frac{T_{s}}{L}\left(v(k)-\hat{v}_{G}(k)\right)
\end{aligned}
$$


Now, eight possible future current values, $i^{p}(k+1)$ will be predicted as,

$$
i^{p}(k+\boldsymbol{I})=\left(\boldsymbol{I}-\frac{R T_{s}}{L}\right) i(k)+\frac{T_{s}}{L}\left(v(k)-\hat{v_{G}}(k)\right)
$$

In equation (8), prediction of $i^{p}(k+1)$, requires the grid voltage value at $k^{\text {th }}$ instant. However, this can be estimated through extrapolation techniques without the need for real time grid voltage measurement. In this work, back extrapolation method is used to estimate the peak value of grid voltage as,

$$
\hat{v_{G}}(k-1)=v(k-1)-\frac{L}{T_{s}} i(k)-\left(R-\frac{L}{T_{s}}\right) i^{p}(k-1)
$$

The back extrapolation estimates the grid voltage for the preceding sample with the assumption that the grid voltage does not vary within the sampling interval. Therefore, the estimated $\hat{v}_{G}(k-1)$ is applied in place of $\hat{v}_{G}(\mathrm{k})$ in equation (8) to complete the current prediction for $k+l^{\text {th }}$ instant. This can be passed on for optimization and further state selection to achieve the control targets.

\section{B. Formulation of Cost function for grid tied inverter}

Generally, the MPC cost function can be developed with the desired electrical quantities in any frame of reference which does not alter the tracking capabilities. Here, the cost function ' $g$ ' for the proposed grid tied inverter is developed to track a current reference in stationary reference frame without any secondary targets, and is expressed as,

$$
g=\left|i_{\alpha}^{*}-i_{\alpha}^{p}\right|+\left|i_{\beta}^{*}-i_{\beta}^{p}\right|
$$

where $i_{\alpha}^{*}{ }^{*} i_{\beta}^{*}, i^{p} \alpha$ and $i_{\beta}^{p}$ are the stationary reference frame coordinates of reference current $\left(i^{*}\right)$ and predicted current $\left(\mathrm{i}^{\mathrm{p}}\right)$ respectively.

Eventually, the $\alpha$ and $\beta$ current quantities are predicted for every sampling instance from equation (8) and (9) and MPC algorithm is executed and the gating signals are obtained to switch the inverter. As the inverter control is actuated at the end of every sampling, it is evident that the iteration size can greatly influence the accuracy of reference tracking. But, this choice of iteration size cannot be independently decided; instead it is dictated by the sampling frequency constraints of the controller. This research is inclined towards the analysis of MPC for varying sampling frequencies in order to identify what could be an optimum choice of iteration size for any selected application and its influence on the reference tracking.

\section{Simulation and Results}

The proposed analysis has been carried out by implementing the grid tied inverter system model of Figure. 1 in MATLAB/Simulink with the specifications of Table 1 using some of the inbuilt blocks as well as custom developed models.

Table 1. Test System Specifications

\begin{tabular}{|c|c|}
\hline Parameters & Value \\
\hline DC Source Voltage & $700 \mathrm{~V}$ \\
\hline Inverter VA Rating & $15 \mathrm{kVA}$ \\
\hline Grid Specifications & $3 \phi, 400 \mathrm{~V}(1-1), 50 \mathrm{~Hz}$ \\
\hline Filter inductance & $0.001 \Omega, 10 \mathrm{mH}$ \\
\hline
\end{tabular}

The inverter power circuit is developed using inbuilt Simulink library block, while the MPC controller is implemented using the 'Embedded MATLAB Function' block. MPC code has two segments (i) system model for prediction and (ii) the cost function and its optimization. This MPC code is developed in such a way to mimic the functionality of any real-time controller giving the optimized switching pattern for the grid tied inverter. The inverter performance index, 
the THD is obtained from inbuilt FFT block while, the average switching frequency and Power loss were computed by customizing the 'User Defined Function' blocks.

The MPC is tested under different test conditions to carry out the proposed analyze.

\section{A. Test Cases}

Test Case 1: A three phase current reference of 15.19A (rms) representing a reference power of $14.87 \mathrm{~kW}$ is applied to MPC controller with a sampling frequency $\left(F_{s}\right)$ of $25 \mathrm{kHz}$.

Test Case 2: Test case 1 is repeated for two more sampling frequencies viz. $50 \mathrm{kHz}$ and 100 $\mathrm{kHz}$.

Test Case 3: A step change in the reference current is introduced at time instants and values as presented in Table 2 with a sampling frequency of $50 \mathrm{kHz}$.

Table 2. Step Change in Current Reference for Test Case 3

\begin{tabular}{|l|c|c|c|}
\hline Time (s) & 0.1 & 0.2 & 0.3 \\
\hline Power Reference $(\mathrm{kW})$ & 11.57 & 14.87 & 9.47 \\
\hline $\begin{array}{l}\text { Change in } I^{*} \\
\text { (as \% of } I^{*} \text { in test case 1) }\end{array}$ & 10 & 0 & -10 \\
\hline
\end{tabular}

Test Case 4: A step change of $\pm 10 \%$ is introduced in the grid voltage, $\mathrm{V}_{\mathrm{G}}$ at the mentioned time points as given in Table 3 with a sampling frequency of $50 \mathrm{kHz}$.

Test Case 5: A step change in grid frequency, $F_{G}$ of $\pm 0.5 \mathrm{~Hz}$ is introduced at the mentioned time points as given in Table 4 with a sampling frequency of $50 \mathrm{kHz}$.

Table 3. Step Change in Grid Voltage for Test Case 4

\begin{tabular}{|l|l|l|l|}
\hline Time (s) & 0.1 & 0.2 & 0.3 \\
\hline $\begin{array}{l}\text { Change in } \mathrm{V}_{\mathrm{G}} \\
\text { (as \% of } \mathrm{V}_{\mathrm{G}} \text { in case 1) }\end{array}$ & 10 & 0 & -10 \\
\hline
\end{tabular}

Table 4. Step Change in Grid Frequency for Case 5

\begin{tabular}{|l|l|l|l|}
\hline Time $(\mathrm{s})$ & 0.1 & 0.2 & 0.3 \\
\hline Change in $\mathrm{F}_{G}(\mathrm{~Hz})$ & 50.5 & 50 & 49.5 \\
\hline
\end{tabular}

The response of the proposed grid tied inverter for all these test cases are presented, summarized and discussed in the following section.

\section{B. Performance Analysis and Observations}

The grid tied inverter performance is quantified using three indices viz. tracking accuracy in $\%$, harmonic profile of inverter current in \% (THDi) and inverter power losses $\left(P_{\text {loss }}\right)$ in W. The tracking accuracy is articulated in terms of magnitude tracking accuracy in $\%\left(\right.$ mag $\left._{i}\right)$ and phase angle tracking accuracy in \% $\left(\right.$ ang $\left._{i}\right)$ as,

$$
\begin{aligned}
& \operatorname{mag}_{i}=\left(1-\left(\frac{I_{r m s}^{*}-I_{r m s}}{I_{r m s}^{*}}\right)\right) \times \mathbf{1 0 0} \\
& \operatorname{ang}_{i}=\left(1-\left(\frac{\theta^{*}-\theta}{\mathbf{3 6 0 ^ { \circ }}}\right)\right) \times \mathbf{1 0 0}
\end{aligned}
$$

where, $I_{r m s}^{*}, I_{r m s}, \theta^{*}$ and $\theta$ are the rms values and phase angles (in degree) of reference current and inverter delivered current respectively. 
Bhadra R. Warrier, et al.

Table 5. Performance Indices for Test Cases 1 to 5

\begin{tabular}{|c|c|c|c|c|c|c|c|c|c|c|}
\hline \multirow[t]{2}{*}{$\begin{array}{l}\text { Test } \\
\text { Case }\end{array}$} & \multirow[t]{2}{*}{$\begin{array}{c}I_{r m s}^{*} \\
(\mathrm{~A})\end{array}$} & \multirow[t]{2}{*}{$\begin{array}{c}F_{s} \\
(\mathrm{kHz})\end{array}$} & \multirow[t]{2}{*}{$\begin{array}{c}V_{G} \\
(\mathrm{~V})\end{array}$} & \multirow[t]{2}{*}{$\begin{array}{c}F_{G} \\
(H z)\end{array}$} & \multirow[t]{2}{*}{$\begin{array}{l}I_{r m s} \\
\text { (A) }\end{array}$} & \multirow[t]{2}{*}{$\begin{array}{c}\text { THDi } \\
(\%)\end{array}$} & \multirow{2}{*}{$\begin{array}{c}\text { Average } \\
\text { switching } \\
\text { frequency } \\
F_{s w}(\mathrm{kHz}) \\
\end{array}$} & \multicolumn{2}{|c|}{$\begin{array}{c}\text { Inverter current } \\
\text { Tracking } \\
\text { Accuracy }(\%)\end{array}$} & \multirow[t]{2}{*}{$\begin{array}{l}P_{\text {loss }} \\
\text { (W) }\end{array}$} \\
\hline & & & & & & & & $\operatorname{mag}_{i}$ & ang $_{i}$ & \\
\hline 1 & 15.19 & 25 & 400 & 50 & 15.08 & 3.73 & 18.7 & 99.28 & 99.83 & 142.2 \\
\hline \multirow{2}{*}{2} & 15.19 & 50 & 400 & 50 & 15.14 & 1.69 & 36.49 & 99.68 & 99.92 & 144 \\
\hline & 15.19 & 100 & 400 & 50 & 15.17 & 0.87 & 77.17 & 99.87 & 99.94 & 146.3 \\
\hline \multirow{3}{*}{3} & 15.19 & 50 & 400 & 50 & 15.14 & 1.78 & 36.61 & 99.68 & 99.92 & 147.5 \\
\hline & 16.71 & 50 & 400 & 50 & 16.67 & 1.67 & 36.61 & 99.77 & 99.92 & 147.5 \\
\hline & 13.67 & 50 & 400 & 50 & 13.62 & 2.1 & 36.61 & 99.65 & 99.92 & 147.5 \\
\hline \multirow{3}{*}{4} & 15.19 & 50 & 400 & 50 & 15.14 & 1.78 & 36.7 & 99.68 & 99.92 & 144.2 \\
\hline & 15.19 & 50 & 440 & 50 & 14.82 & 3.58 & 36.7 & 97.58 & 99.78 & 144.2 \\
\hline & 15.19 & 50 & 360 & 50 & 15.16 & 1.7 & 36.7 & 99.80 & 99.87 & 144.2 \\
\hline \multirow{3}{*}{5} & 15.19 & 50 & 400 & 50 & 15.13 & 1.89 & 38.09 & 99.60 & 99.92 & 149.6 \\
\hline & 15.19 & 50 & 400 & 50.5 & 15.14 & 1.8 & 38.09 & 99.68 & 99.92 & 149.6 \\
\hline & 15.19 & 50 & 400 & 49.5 & 15.13 & 1.82 & 36.57 & 99.60 & 99.92 & 149.6 \\
\hline
\end{tabular}

By manipulation of the switching states of the inverter within a given simulation time, the average switching frequency $\left(F_{s w}\right)$ is calculated for all the test cases. The total losses of the inverter with the proposed MPC are estimated using the basic power loss equations of MOSFET, [18] and used for performance analysis. The total power loss of the inverter is found to be as high as $1.01 \%$ of its rated power for an average switching frequency of $36.87 \mathrm{kHz}$. The other performance indices are summarized in Table 5. From these results it is ascertained that the MPC inverter exhibits increased efficiency with better tracking accuracy.
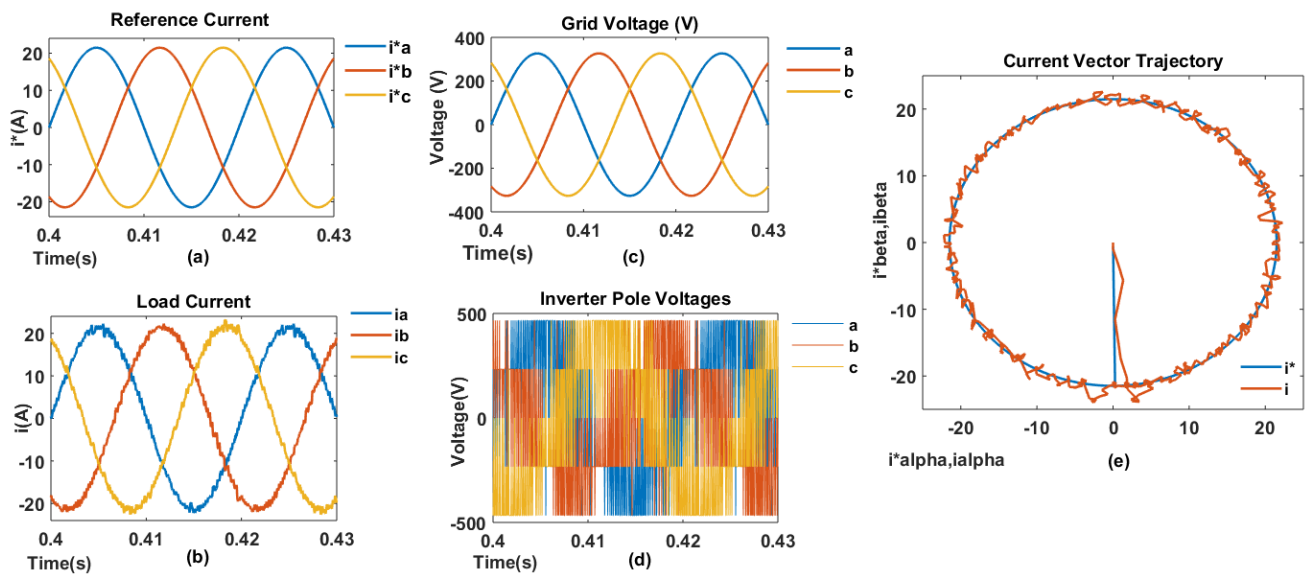

Figure 2. Time Response of proposed control for test case 1: (a) Applied $i^{*}$, (b) Observed $i$, (c) Observed grid voltage, (d) Observed inverter pole voltage, (e) $I^{*}$, Current Vector trajectory of $i *$ and ,I the Current Vector trajectory of $i$.

The applied instantaneous three phase current reference $(i *)$ and observed system variables for test case 1 are depicted in Figure 2 (a) to (d). The inverter current tracking accuracy is $99 \%$ across all the cases. In Figure 2 (e) $I$, the trajectory of inverter current vector $(i)$ and $I^{*}$, the trajectory of reference current vector $i^{*}$ exhibits a high degree of agreement with each other except minor deviations. 

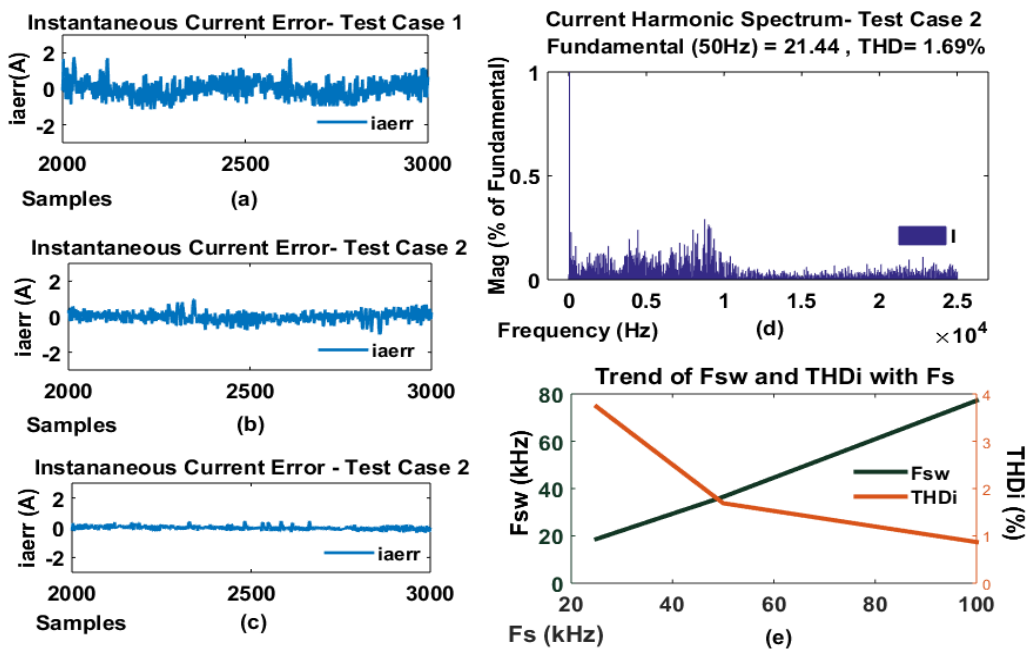

Figure 3. (a) to (c) Instantaneous current error of test cases 1 and 2 with $F_{s}$ of 25,50 and 100 $\mathrm{kHz}$ respectively, (d) Current harmonic spectrum for test case 2, (e) Trend of $F_{s w}$ and THDi with varying sampling frequency.

The reduction in maximum current error per sample with increase in $F_{s}$ can be observed from Figure.3 (a) to (c) where 'iaerr' is the current error for phase a. The harmonic profile of the delivered current is $1.69 \%$ as seen from Figure. 3 (d) which is well within the stipulated IEEE limits.
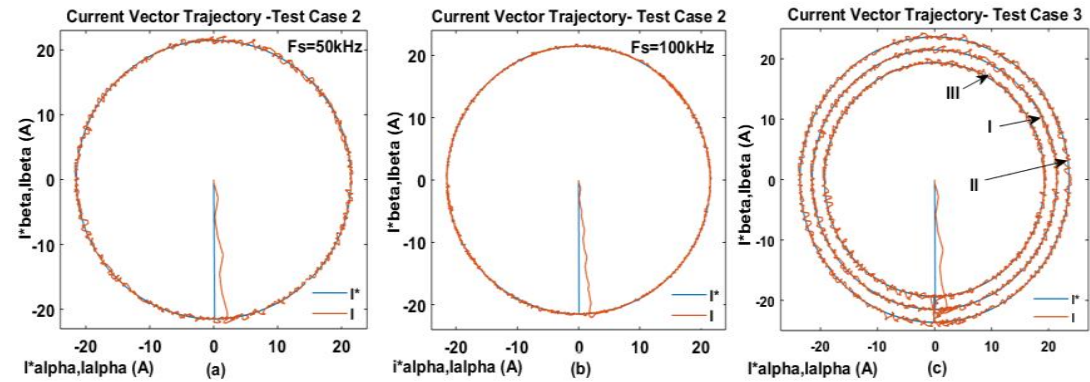

Figure 4. (a) \& (b) I* and I for case 2 with $F s=50 \mathrm{kHz}$ and $100 \mathrm{kHz}$ respectively, (c) I* and I for case 3 with II and III representing a $\pm 10 \%$ step change in I* magnitude from trajectory I at $0.1 \mathrm{~s}$ and $0.3 \mathrm{~s}$ respectively.

The average switching frequency is found to be approximately $1 / 8^{\text {th }}$ of its sampling frequency in all the cases as evident from Table 5.; the inverter power loss, $P_{\text {loss }}$ also escalates with increase in sampling frequency. This is the result of higher switching frequencies resulted due to higher sampling frequencies. From Figure.4 (a),(b) and (c), it is evident that tracking accuracy improves as $\mathrm{F}_{\mathrm{s}}$ increases; at higher $\mathrm{F}_{\mathrm{s}}$, the predictions being much closer, the reference is better followed.

However, the harmonic spectrum in all the cases is wide spread up to half of $F_{s}$ as seen in Figure. 3 (d). This is one of the innate characteristics of any direct current control techniques of inverters. But, this spread spectrum can be shaped to any specific center frequency with small side bands with the addition of an secondary target which is beyond the scope of this paper. Taking into account the quality of current delivered with reduced total inverter losses, $F_{s}=50$ $\mathrm{kHz}$ is found to be an optimal choice as seen from Figure. 3 (e). Hence all the test cases from 2 to 5 are carried out with this sampling rate. 

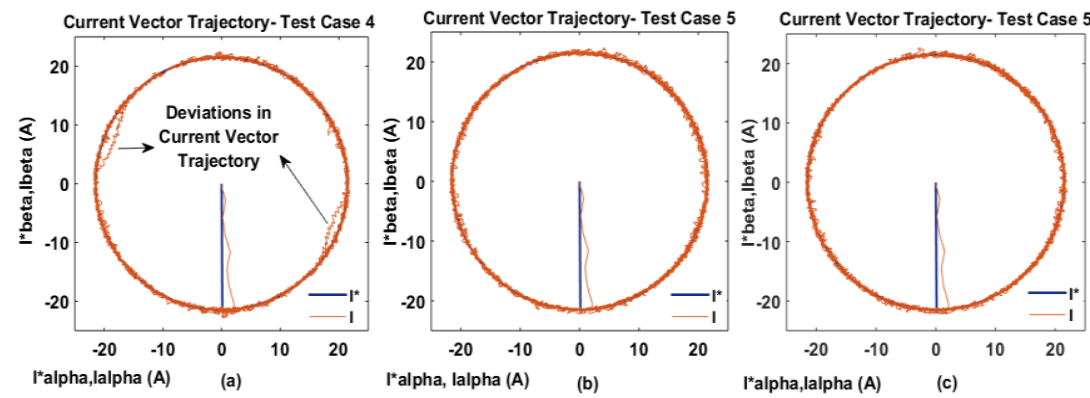

Figure 5. (a) $I^{*}$ and $I$ for case 4 with $\pm 10 \%$ step change in $\mathrm{V}_{\mathrm{G}}$ magnitude at $0.1 \mathrm{~s}$ and $0.3 \mathrm{~s}$ respectively, (b) \& (c) $I^{*}$ and $I$ for case 5 with $\pm 0.5 \mathrm{~Hz}$ step change in $F_{\mathrm{G}}$ frequency at $0.1 \mathrm{~s}$ and $0.3 \mathrm{~s}$ respectively.
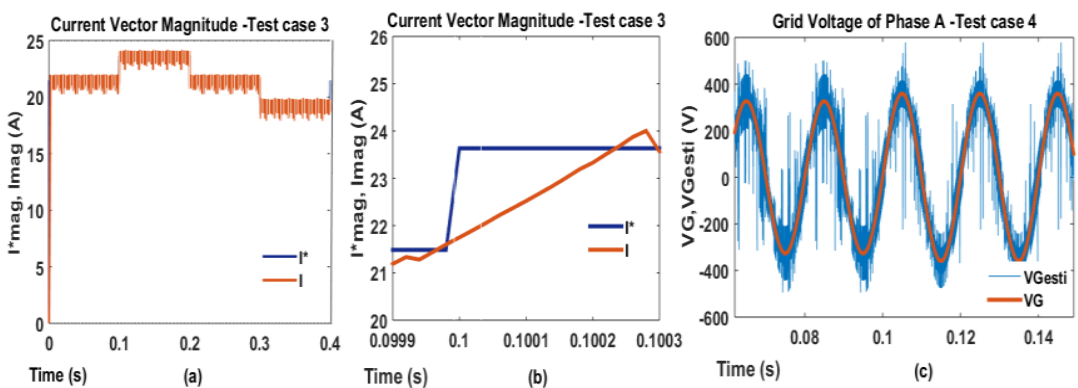

Figure 6. (a) Magnitude of $I^{*}$ and $I$ test case 3 with $\pm 10 \%$ step change in $I^{*}$ magnitude at $0.1 \mathrm{~s}$ and $0.3 \mathrm{~s}$ respectively, (b) Magnified view of transition for test case 3, (c) $V_{G_{-}} a$ and $V_{\text {Gesti_a }} a$ with step change of $\pm 10 \%$ of $V_{G \_} a$ at $0.1 \mathrm{~s}$ and $0.3 \mathrm{~s}$ respectively.

Test case 3 to 5 tested the dynamics of the proposed MPC to depict typical scenarios in grid connected inverters, viz. the change in power available from the source, grid voltage and frequency regulation etc. Considering the above scenarios, step change is introduced in (i) the reference current amplitude, (ii) the grid voltage amplitude and (iii) the grid frequency. In all these cases, the inverter current vector trajectory aligns well with the reference trajectory as presented in Figure.5 and Figure. 6. It is worth mentioning here that when compared to the current trajectory in Figure.2 (e) with $\mathrm{F}_{\mathrm{s}}$ of $25 \mathrm{kHz}$, the trajectories in Figure. 5 (a) and (b) exhibit narrow and highly narrow tracking paths respectively due to higher $\mathrm{F}_{\mathrm{s}}$ considered.

The following characteristic features observed from the results of the proposed case studies prove that the MPC based grid tied inverter exhibits superior dynamic tracking proficiency

(i) When a step change in power reference is introduced in test case 3, the current delivered by the inverter is seen to follow it without much of a transition time and without reduction in its tracking accuracy as seen in Figure 5.(c) with trajectory 'I' corresponding to the inverter current at steady state with 15.19A rms whereas trajectories II and III represents step change of $\pm 10 \%$ in rms current respectively. A similar observation is also noticeable in case of Figure 6 (a) where $I^{*}$ is increased by $10 \%$ at the instant of $0.1 \mathrm{~s}$ and immediately $\mathrm{I}$ is able to capture this variation without much delay.

(ii) In all the dynamic test conditions, the time taken to predict the variation is found to be $250 \mu \mathrm{s}$, which is much less than a sampling interval. That is, immediately after any step variation, the new value of current is obtained by the MPC algorithm much before the next sampling instant.

(iii) Figure.5 (a) shows the results of test case 4, when there is a step increase in grid voltage magnitude at the instant $0.1 \mathrm{~s}$ by $10 \%$, the current vector trajectory of inverter current is almost 
found to trail along the reference trajectory. Even though at the instant of step change a small deviation in trajectory is evident, the effective dynamic optimization involved in proposed MPC is able to regain the tracking capability without much delay.

The actual grid voltage $\left(V_{G}\right)$ and discretely estimated grid voltages $\left(V_{G e s t i}\right)$ for test case 4 are shown in Figure 6 (c) from which the variation at $0.1 \mathrm{~s}$ is effectively estimated by the MPC. Here, a high tracking accuracy is observed; this is due to better back extrapolation computation even under varying grid voltage conditions.

(iv) Figure 6 (b) and (c) shows the current vector trajectories for step changes in grid frequency of $\pm 0.5 \mathrm{~Hz}$ at $0.1 \mathrm{~s}$ and $0.3 \mathrm{~s}$ respectively. The deviations of ' $I$ ' at the instant of transition is not much significant and the inverter is still capable of meeting the specified control target with MPC with tracking accuracies of as high as $99.6 \%$ and $99.92 \%$ in magnitude and angle respectively.

Thus, the grid tied inverter is found to showcase excellent tracking capacity matrix with low harmonic distortions and good dynamic response at low and medium sampling rates. The proposed analysis on MPC, recapitulate that it is an effective and efficient alternative control technique to classical current controls with voltage based PWM techniques and other implicit modulator techniques.

\section{Conclusion}

In this paper a recent modulation technique, MPC is applied to a grid tied inverter and investigated on its capability to achieve high reference tracking accuracies and its dependency on the sampling frequency. Closer current predictions gave better tracking accuracy for higher and moderate sampling frequencies. It is elucidated that, the sampling rate selection is a critical design criterion, as it has to be large enough to accommodate the computations as well as current predictions and small enough to result higher tracking accuracy. This diverge demand and their tradeoff has initiated this investigation on the effect of sampling rate on MPC and its performance on a grid tied inverter. The reference trailing capability assessed in terms of tracking accuracy revealed a high degree of compliance between the reference and delivered currents for high and medium sampling frequencies with good harmonic profile. Yet, a reasonable tracking accuracy has been observed even for smaller sampling rates with a reduced inverter loss. Even though the current THD is low, the current harmonic spectrum across all cases are found to be spread up to half of the respective sampling frequencies. Another important observation from the study is on the average switching frequency which is seen as $1 / 8^{\text {th }}$ of the sampling frequency of any value.

This spread spectrum of harmonics can be resolved by suitably appending the cost function with auxiliary control target aimed to restrict the current spectrum centered around a specific frequency. The proficiency in dynamic response demonstrated by MPC in prediction as well as estimation substantiates the merits of this technique to complement the ambitious requirements of future power converter controls.

\section{Acknowledgement}

The authors would like to express their sincere gratitude to the research support offered by Visvesvaraya PHD Scheme for Electronics and IT, Ministry of Electronics and Information Technology, Government of India and Digital India Corporation.

\section{References}

[1]. A. Vijayakumari, Bhadra R.Warrier, and N.Devarajan. "Topologies and control of grid connected power converters." Proc. of ICCPCT., IEEE, pp. 401-410,2014.

[2]. Blaabjerg, F., Teodorescu, R., Liserre, M. and Timbus, A.V. "Overview of control and grid synchronization for distributed power generation systems", IEEE Transactions on industrial electronics, vol. 53, no.5, pp.1398-1409, 2006. 
Bhadra R. Warrier, et al.

[3]. Kazmierkowski, M.P. and Malesani, L., "Current control techniques for three-phase voltage-source PWM converters: A survey", IEEE Transactions on industrial electronics, vol. 45, no.5, pp.691-703,1998.

[4]. Rodriguez, Jose, and Patricio Cortes.," Predictive control of power converters and electrical drives", vol. 40., John Wiley \& Sons, 2012.

[5]. Leon, Jose I., Samir Kouro, Leopoldo G. Franquelo, Jose Rodriguez, and Bin Wu. "The essential role and the continuous evolution of modulation techniques for voltage-source inverters in the past, present, and future power electronics." IEEE Transactions on Industrial Electronics, vol. 63, no. 5 pp: 2688-2701,2016.

[6]. Ojha, A., Chaturvedi, P., Mittal, A., \& Jain, S., "Neutral Point Potential Control for Three Phase 3-level Neutral Point Clamped Active Front End Converter", International Journal on Electrical Engineering \& Informatics, vol.9, no.2, 2017.

[7]. Magham, Hesam Rahbari, Erfan Ma'ali Amiri, Javad Shokrollahi Moghani, Babak Abdi, and G. B. Gharehpetian, "DC link voltage effects on the performance of the two current control strategies of voltage source converters.", International Journal on Electrical Engineering and Informatics, vol.5, no. 1, pp:105, 2013.

[8]. Balaguer, I. J., Lei, Q., Yang, S., Supatti, U., \& Peng, F. Z, Control for grid-connected and intentional islanding operations of distributed power generation. IEEE transactions on industrial electronics, vol.58, no.1, pp: 147-157, 2011.

[9]. Kouro, S., Cortés, P., Vargas, R., Ammann, U. and Rodríguez, J.," Model predictive control-A simple and powerful method to control power converters", IEEE Transactions on Industrial Electronics, vol. 56, no.6, pp.1826-1838,2009.

[10]. Vazquez, S., Leon, J.I., Franquelo, L.G., Rodriguez, J., Young, H.A., Marquez, A. and Zanchetta, P., "Model predictive control: A review of its applications in power electronics", IEEE Industrial Electronics Magazine, vol. 8,no.1, pp.16-31,2014.

[11]. Rodriguez, J., Pontt, J., Silva, C.A., Correa, P., Lezana, P., Cortés, P. and Ammann, U., "Predictive current control of a voltage source inverter", IEEE Transactions on Industrial Electronics, vol.54, no.1, pp.495-503, 2007.

[12]. Cortes, Patricio, Jose Rodriguez, Cesar Silva, and Alexis Flores. "Delay compensation in model predictive current control of a three-phase inverter." IEEE Transactions on Industrial Electronics, vol.59, no. 2, pp:1323-1325,2011.

[13]. Bordons, Carlos, and Carlos Montero. "Basic principles of MPC for power converters: Bridging the gap between theory and practice." IEEE Industrial Electronics Magazine, vol.9, no. 3 pp:31-43, 2015.

[14]. Bhadra R. Warrier, A. Vijayakumari, Sasi.K Kottayil, Enhanced Dynamic Performance in Grid Tied Bidirectional Converter with Direct Power Model Predictive Control, International Journal of Power Electronics, Inderscience Publications, 2018 [in press]

[15]. Holmes, D. Grahame, and Thomas A. Lipo. "Pulse width modulation for power converters: principles and practice.", John Wiley \& Sons,vol. 18., 2003.

[16]. Clarke, D. W., and R. Scattolini. "Constrained receding-horizon predictive control." In IEE Proceedings D (Control Theory and Applications), vol. 138, no. 4, pp. 347-354. IET Digital Library, 1991.

[17]. Bouaziz, Bechir, Faouzi Bacha, and Moncef Gasmi, "A sliding mode approach into constant switching frequency direct power control of a grid connected voltage source converter." International Journal on Electrical Engineering and Informatics, vol. 7, no. 1, $p p: 42,2015$.

[18]. Mohan, Ned, and Tore M. Undeland, "Power electronics: converters, applications, and design.", John Wiley \& Sons, 2007.

[19]. Casanellas, F.,"Losses in PWM inverters using IGBTs". IEEE Proceedings-Electric Power Applications", vol. 141, no.5, pp.235-239, 1994. 


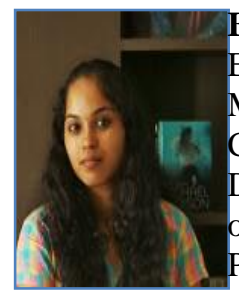

Bhadra R Warrier received B.Tech degree in Electrical and Electronics Engineering from Cochin University of Science and Technology, India and M.Tech degree in Power Electronics from Amrita School of Engineering, Coimbatore, India in 2012 and 2014 respectively. She is currently perusing her Doctoral Degree under the guidance of Dr. A. Vijayakumari in Amrita School of Engineering, Coimbatore, India. She is also awarded with Visvesvaraya Ph.D. Scheme of Electronics and Information Technology, DeitY, Government of India's research scholarship. Her research interests include Power Converter Control, Topology and Modelling, Renewable Energy Systems, Grid Synchronization Issues, Variational Mode Decomposition, Model Predictive Control etc.

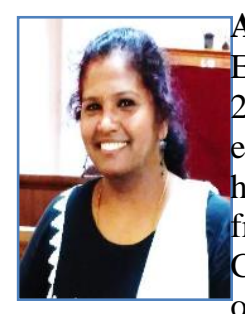

A. Vijayakumari received the B.E. and M.E. degrees in Electrical and Electronics engineering from Bharathiar University, Coimbatore in 1991 and 2001 respectively. She received her Ph.D degree in Electrical and Electronics engineering from Anna University, Chennai in 2014. From 1991 to 1992 she has been with Bharath Electronics Ltd., Madras, as Govt. of India Trainee and from 1993 to 1995 served as Project Engineer at Easwari Associates, Coimbatore in R\&D department. She has been a guest lecturer in Govt. College of Technology, Coimbatore from 1995 to 1999. Since 2001 she is with Amrita University as Lecturer, senior Lecturer, Assistant Professor and presently Associate professor in the department of Electrical and Electronics Engineering. Her research area includes Power Electronics, Power Converters for smart micro-grid, solar and wind energy conversion systems and model predictive control for power electronics and electric vehicle drives.

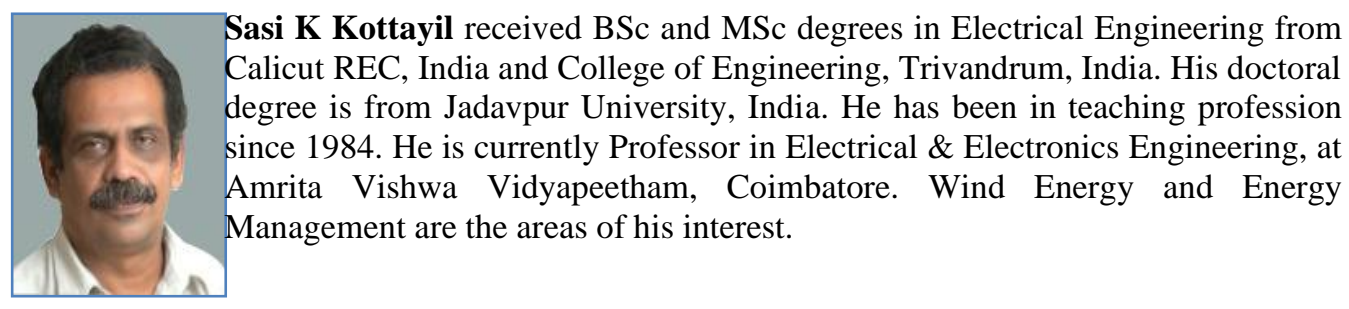

